\title{
APPLICATION OF THE ANALYTIC NETWORK PROCESS (ANP) TO ESTABLISH WEIGHTS IN ORDER TO RE-ACCREDIT A PROGRAM OF A UNIVERSITY
}

\author{
Diana Lesmes* \\ Industrial Engineering Department \\ Universidad de los Andes \\ Bogotá, Colombia \\ E-mail: d-lesmes@uniandes.edu.co \\ Mario Castillo \\ Industrial Engineering Department \\ Universidad de los Andes \\ Bogotá, Colombia \\ E-mail: mcastill@uniandes.edu.co \\ Roberto Zarama \\ Industrial Engineering Department \\ Universidad de los Andes \\ Bogotá, Colombia \\ E-mail: rzarama@uniandes.edu.co
}

\begin{abstract}
Colombian higher education institutions have an interest in obtaining recognized high quality standards. This recognition is obtained by an accreditation granted by the Colombian Government. The Consejo Nacional de Acreditación (CNA) is the academic body responsible for coordinating such process. This paper is based on the re-accreditation process of the industrial engineering undergraduate program at the Universidad de los Andes in Bogotá. The paper focuses on the process for weighing the components (factors) and criteria (characteristics) established by the CNA. For this process, the Industrial Engineering Department organized a workshop where academics deliberated about the weights they had to assign to each component and criteria. Due to the fact that many of the criteria are related to each other, we proposed to use the ANP for establishing the weights. The ANP model we built was complex because the network was dense and also because it was necessary to consider a high number of criteria for its construction. The results obtained were significantly different from those obtained at the workshop. The ANP model results indicate that the source components of the network had the higher weights, whereas the sink components had the lowest weights. In the source components the proportion of criteria within the component that influences on other criteria is greater than the influences they receive; the same argument works for the sink components. The construction of the ANP model was essential because the weights obtained were used to make the self-assessment of the program.
\end{abstract}

Keywords: Analytic Network Process, Accreditation, Education

\section{Introduction}

\footnotetext{
${ }^{*}$ Corresponding author
} 
In order to re-accredit the Industrial Engineering Undergraduate Program, the Universidad de los Andes had to establish the weights of the factors and characteristics determined by the CNA. In order to establish those weights, the Industrial Engineering Department organized a workshop where academics deliberated about the weights they had to assign to each factor and characteristic. One of the participants of this workshop, and coauthor of the paper, was aware of the ANP and pointed out that many of the characteristics are related to each other. Due to that fact, we proposed to use the ANP model for establishing the weights. The results we obtained were used by the Industrial Engineering Department to evaluate the program's performance.

This paper is organized as follows: In section 2, we describe the accreditation process. In section 3, we present the theory and the methodology used in the research. In section 4, we show the ANP model proposed for assessing the weights of the factors and characteristics; or components and criteria, respectively. In section 5, we compare the results obtained with the ANP model and the direct weight assignation method. Finally, in section 6, we describe the research conclusions.

\section{The accreditation process}

The CNA identified 8 components and 42 criteria to evaluate the quality of an undergraduate program. In this section, we make a brief description of them. The components and the criteria definition was found in the article Lineamiento para la Acreditación de Programas (Consejo Nacional de Acreditación, 2006).

Component 1. Institution's Mission and project is composed by the following criteria:

Criterion 1. Institution's Mission: The institution's mission enters the public domain and is expressed in terms of academic and administrative processes and objectives. The mission makes explicit the institution's commitment with the higher education's standards and quality.

Criterion 2. Institution's project: The institution's project orientates the educative process and the program's administration. It is a fundamental reference in the decision making process related to the curriculum, research and internationalization, among others.

Criterion 3. Program's educational project: The program enters the public domain and is coherent with the institutional project. It points out the objectives, the basic guidelines of the curriculum and the goals of its construction, among others.

Criterion 4. Program's academic relevance and social pertinence: The program is relevant academically and responds to national and international needs.

Component 2. Characteristics associated with the students. It is composed by the following criteria:

Criterion 5. Admission mechanisms: The institution applies equitable admission mechanisms based on the merits of the candidates.

Criterion 6. Admitted students' number and quality: Admitted students' number and quality considers the capacity of the institution and the program to make students finish their studies.

Criterion 7. Students' retention and dropout: The program has defined evaluation systems, desertion monitoring and mechanisms for its control.

Criterion 8. Involvement in integral formation activities: The program promotes the students' participation in academic activities, in research projects, in artistic activities, sports. 


\section{Lesmes, M. Castillo, R. Zarama/ Application of ANP to establish weights}

Criterion 9. Student regulation: The institution has a student regulation officially approved and sufficiently spread. It defines the rights and duties, the disciplinary regime, the participation mechanisms and the exigencies of permanence and graduation.

Component 3. Characteristics associated with the professors. It is composed by the following criteria:

Criterion 10. Professors' selection and hiring: The institution has defined clear academic criteria for selecting its professors and, therefore, evaluates them with no preferences.

Criterion 11. Faculty statute: Contents the following aspects: regime for selection, contracting, promotion, retirement and any administrative situation that can be considered. It also defines the rights and duties, the participation mechanisms, the disciplinary regime and stimuli for good performance.

Criterion 12. Professors' number, dedication and formation degree: Professors' quantity and quality are adequate to develop the teaching activities and research.

Criterion 13. Faculty's development: Politics and programs exist for ensuring the faculty's development to achieve the objectives and needs of the program.

Criterion 14. Interaction with academic communities: The interaction with the national and international academic communities is coherent with the objectives and needs of the program.

Criterion 15. Stimulus for teaching and research, social extension or projection and international cooperation: The institution has defined a regime of stimulus to recognize the qualified exercise of the research and teaching functions, the social projection or extension and the international cooperation.

Criterion 16. Production of teaching material: Teachers produce material for their classes that allows professors to make periodical students evaluation based on criteria and mechanisms already defined.

Criterion 17. Merit remuneration: The salary that the teacher receives is in agreement with their professional merits and obeys the legal requirements.

Component 4. Characteristics associated with the academic process. It is composed by the following criteria:

Criterion 18. Curriculum integrality: The curriculum contributes to the formation of values, attitudes, aptitudes, skills, knowledge and methods related to the profession.

Criterion 19. Curriculum flexibility: The curriculum is sufficiently flexible to stay updated and pertinent, and to optimize the students' transit through the program and the institution.

Criterion 20. Curriculum interdisciplinary: The program recognizes, promotes and stimulates the interaction between students and professors from different programs with other areas of knowledge.

Criterion 21. Program's national e international relations: National e international communities are taken as reference to update the plan of studies and the interaction with other programs is stimulated.

Criterion 22. Methodology of teaching and learning: The pedagogical methods employed in the development of the studies plan's contents are coherent with the nature of the program's needs and objectives, and with the number of students that participate in the teaching activity. 
Criterion 23. Students' assessment system: It considers clear universal and equitable politics and rules that are applied having under consideration the nature of the different academic activities.

Criterion 24. Students' works: The works carried out by the students help to achieve the program's objectives and the development of skills required by the professional market.

Criterion 25. Evaluation and self-regulation of the program: Clear criteria and procedures exist to evaluate objectives, processes and achievement of the program. The participation of students, professors and alumni is considered to evaluate the relevance of the program for the society.

Criterion 26. Formation for research: The program promotes research to encourage autonomous thinking, which allows academics to formulate problems and solution alternatives.

Criterion 27. Commitment with research: In concordance with the institution's project, the program has teachers that spend significant time on research related to the program.

Criterion 28. Social extension and projection: The program has defined mechanisms to face environment problems academically, promotes bonds with different sectors of the society and incorporates the results of these experiences in the plan of studies.

Criterion 29. Library resources: The program has enough qualified bibliographic resources, updated and accessible to the members of the academic community, and promotes students to have contact with the texts and materials.

Criterion 30. Information and communication resources: In the academic process, the teachers and students have enough information and communication resources, which are updated and are appropriate for the nature of the program and the number of users.

Criterion 31. Educational support resources: The program has enough labs, equipments and audiovisual aids.

Component 5. Characteristics associated with the institutional welfare. It is compose by the following:

Criterion 32. University's politics, programs and welfare services: The university welfare services are enough, adequate and accessible. They are used by teachers, students and administrative personal and responds to an integral politic of the university welfare defined by the institution.

Component 6. Characteristics associated with the organization, administration and management. It is composed by the following criteria:

Criterion 33. Program's organization, administration and management: The program's organization, administration and management favor the development and the functions of teaching and research, among others. The people in charge of the program's administration are sufficient in number and dedication and have the formation required for their functions’ performance.

Criterion 34. Information and communication systems: The program has effective internal communication mechanisms and internal information systems that are stable and accessible.

Criterion 35. Program management: The management rules are clearly defined and known by the users. 


\section{Lesmes, M. Castillo, R. Zarama/ Application of ANP to establish weights}

Criterion 36. Program promotion: The institution and the program make public their educational offer with transparence and truthfulness.

Component 7. Characteristics associated with the graduates and impact on the environment. It is composed by the following criteria:

Criterion 37. Program's influence on the environment: As one of its field of action, the program exerts a positive influence on the environment. This influence is subject of systematic analysis.

Criterion 38. Tracking of the graduates: The program tracks the graduates location and activities. The program is concerned about verifying if these activities correspond to the purpose of the program.

Criterion 39. Impact of the graduates on the social and academic environment: The program's graduates are distinguished by their performance in their occupation and the quality of the education they received.

Component 8. Characteristics associated with the physical and the financial resources. It is composed by the following criteria:

Criterion 40. Physical resources: The program has proper installations for the development of its functions and it receives proper maintenance.

Criterion 41. Program budget: The program has sufficient budget to operate, according to its nature and objectives.

Criterion 42. Management resources: The administration of the physical and financial resources is efficient, effective, transparent, and meets the current legislation.

The accreditation process of an undergraduate program has three stages, as shown in Figure 1 . The description of these stages was found in the article Orientación para la Evaluación Externa con Fines de Acreditación Institucional (Consejo Nacional de Acreditación, 2006). The first stage corresponds to a self-evaluation. In this step, the institution assigns weights to the component and the criteria that the CNA considers an undergraduate program must have. The second stage corresponds to an external evaluation, which is made by a commission designed by the CNA. The commission classify the institution's quality based on the self-evaluation inform. In the final evaluation, which is completed by the CNA, the commission emits an opinion about the program's quality based on the external evaluation report. If the evaluation is satisfactory, it will lead to accrediting the undergraduate program by the Colombian National Minister of Education.

$$
\begin{aligned}
& \text { Self-evaluation } \\
& \text { - In charge of the } \\
& \text { higher education } \\
& \text { institution }
\end{aligned}
$$

External evaluation

- In charge of the academic peers
Final evaluation

-In charge of the CNA

Figure 1. Accreditation process stages 


\section{Research theory and methodology}

In this section we make a general description of the ANP theory, and then, we describe the methodology that we are going to follow for the development of this paper.

\subsection{ANP theory overview}

The Analytic Hierarchy Process (AHP) and its extension, the ANP, are tools used in multi-criteria decision analysis. The AHP consists of one goal, some criteria and alternatives, which are arranged in a hierarchy structure where the lower level elements influence on higher level elements, as shown in Figure 2. Nevertheless, many decision problems cannot be structured in a hierarchy because they involve dependences between the alternatives, dependences of the criteria that belong to a same level, or dependence of higher level elements on lower level elements, besides the mentioned relations (Saaty $\mathrm{T}$. L., 2001, pp. 83-84, 180). This concern motivated Thomas Saaty to develop the ANP, which makes possible a natural development of the problem because it does not impose a structure (Saaty T. L., 2001, p. 181). As Figure 2 shows, a network can be extended in all directions.

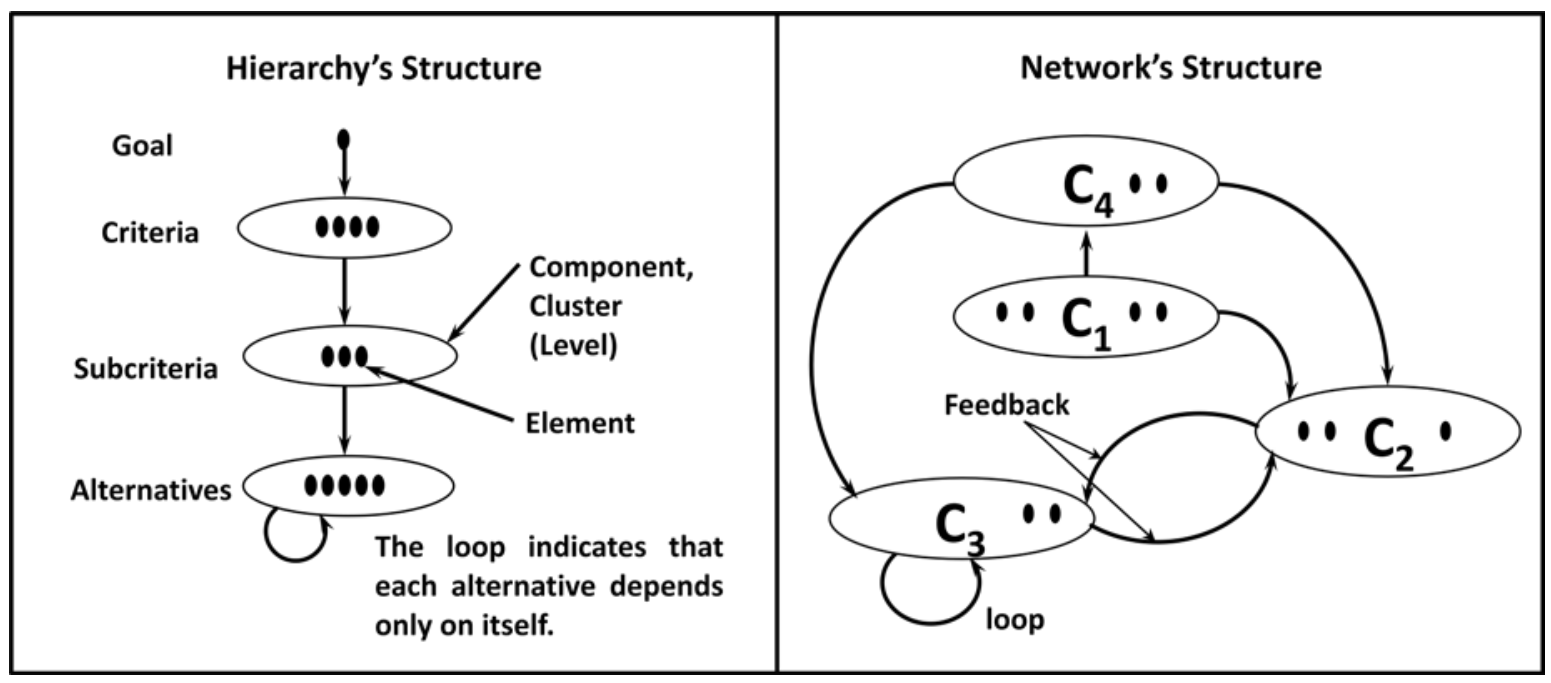

Figure 2. Hierarchy’s and network’s structures

In order to obtain the priorities to rank alternatives in a decision model, the ANP uses pairwise comparisons. A pairwise comparison matrix is formed when comparing a pair or more pairs of elements with respect to a reference element, which remains unchangeable for all the comparisons. To make such comparison, Thomas Saaty developed the scale shown in Table 1, which allows measuring the strength of the judgments (Saaty T. L., 2008, p. 7).

Table 1. Saaty’s fundamental scale

\begin{tabular}{|l|l|}
\hline Intensity of importance & Definition \\
\hline 1 & Equal importance \\
\hline 3 & Moderate importance \\
\hline 5 & Strong importance \\
\hline 7 & Very strong importance \\
\hline 9 & Extreme importance \\
\hline $2,4,6,8$ & Intermediate values \\
\hline
\end{tabular}


In order to validate the judgments' consistency of the pairwise comparisons matrices, the consistency ration (C.R.) of the matrices is calculated. According to Saaty (2001, p. 57), the consistency ratio should be less or equal to 0.1 , where 0.2 is the maximum value that can be tolerated. In order to calculate the consistency ratio of matrix A, for example, it is necessary first to determine the consistency index:

$$
\text { Consistency Index of Matrix } A=C . I .(A)=\frac{\lambda_{\max }-n}{n-1}
$$

Matrix theory states that a reciprocal matrix, as the case of the pairwise comparison matrix, is consistent when the maximum matrix's eigenvalue is equal to the size of a square matrix $n \times n$. In this sense, the consistency index should approach to zero. A pairwise comparison matrix is consistent if their judgments are ruled by the transitivity principal (Saaty T. L., 2005, pág. 51). Before calculating the C.R., it is necessary to estimate the averaged random consistency index (R.I.), which is obtained from random reciprocal matrix using Saaty's fundamental scale. Assuming that a random matrix does not have to be necessarily consistent, it is expected that the R.I. should be greater than the C.I. (Saaty T. L., 2001, p. 57), and therefore, the C.R. should be small. The C.R. of matrix A is defined as follows:

$$
\text { Consistency Ratio of matrix } A=C . R .(A)=\frac{C . I .(A)}{R . I .}
$$

From the pairwise comparison matrices is obtained an eigenvector of priorities. Those priorities allow comparing the relative importance of some elements respect to the criteria or the element to which they were compared. When all the eigenvector of the decision model are calculated, these are used to form the unweighted supermatrix. To construct this matrix supposes that there are $\mathrm{N}$ components. Also, it supposes that the component $\mathrm{h}$, denoted by $\mathrm{C}_{\mathrm{h}}, \mathrm{h}=1, \ldots, \mathrm{N}$, has $\mathrm{n}_{\mathrm{h}}$ elements, that are denoted by $\mathrm{e}_{\mathrm{h} 1}, \mathrm{e}_{\mathrm{h} 2}, \ldots, e_{h n_{k}}$ as shown in Figure 3 (Saaty T. L., 2005, pág. 51).

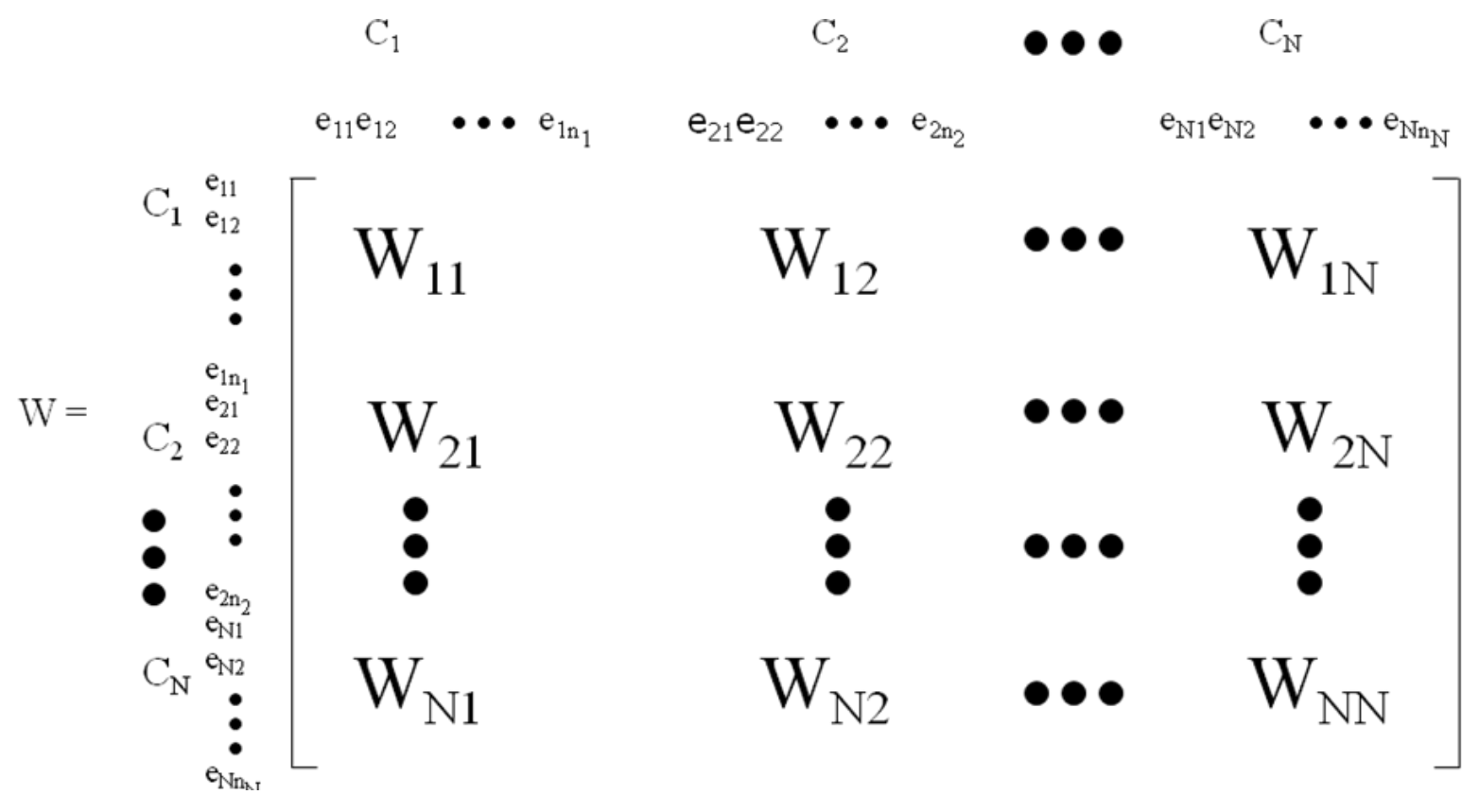

Figure 3. Supermatrix structure

In the supermatrix, each of the eigenvector is assigned to the correspondent column. The elements in the superior row are the criteria used as reference for making the comparison. If there is no influence of the 
left column element with respect to the criteria in the superior row, the correspondent value in the supermatrix is cero. The next step, according to Saaty methodology, is to construct the weighted supermatrix using the component matrix to weight the supermatrix previously assembled. To calculate the weighted supermatrix is a need to make the matrix stochastic. This condition is necessary for obtaining the resulting limit supermatrix. This matrix is calculated elevating the weighted supermatrix to the nth power. This procedure allows capturing the transmission of influences from all the paths of the network. For example, to obtain indirect influences through a third element, the weighted supermatrix must be powered to the square (2001, págs. 94-97).

The other aspects that make up a complex decision will not be described because they are not necessary for developing the ANP model proposed in this paper. In the literature, we found many models that do not require the structure of a complex decision. In these models, ANP is usually used for selecting alternatives or making estimations, as the model for accessing the McDonalds' market participation. Instead of that, the objective of the ANP model developed in this paper is to obtain the priorities' weights of the criteria needed for evaluating the quality of an undergraduate program. A similar application was developed by Lin, Y. - H. et al. (2008). In this application, they use ANP to establish a performance assessment model for business intelligence systems.

\subsection{Research methodology}

The methodology that we developed for this research is structured in the steps shown in Figure 4. Steps 1, 2 and 3 correspond to section 4 of this research. Step 4 corresponds to section 5 and step 5 corresponds to section 6 .

\begin{tabular}{|c|}
\hline Step 1: To construct the network \\
\hline Objective: To identify the interdependence relations among criteria \\
\hline Step 2: To survey the experts \\
\hline Objective: To establish the pairwise comparison matrices' judgements \\
\hline Step 3: To apply the ANP method using Super Decision Software \\
\hline Objectives: To test the the pairwise comparisons' consistency. To obtain the weights. \\
\hline Step 4: To compare the results obtained in the workshop versus the ANP model \\
\hline Objective: To reach an undertanding about the components and criteria weights \\
\hline Step 5: To formulate the conclusions \\
\hline Objective: To describe the contribution of the ANP model to the accreditation process \\
\hline
\end{tabular}

Figure 4. Research methodology 


\section{The ANP accreditation model}

The purpose of this model is to assist the Industrial Engineering Department to establish the relative importance of the components and the criteria already defined by the CNA. This step of the accreditation process in an undergraduate program is very important because the priorities' weights, assigned to the components and the criteria, would be used in the evaluation of the program's global quality.

\subsection{Network construction}

This is the first step for developing the ANP accreditation model. Before determining the interdependences among the criteria, we grouped some criteria of component 4, characteristics associated with the academic process. We grouped criteria 18, 19 and 20 into one criterion because all of them were related to curriculum. We also grouped criteria 22, 23 and 24 into one criterion because all of them were related to education methodology. Criteria 26 and 27 were also grouped together because they were related to research. Finally, criteria 29, 30 and 31 were grouped together because they were related to resources. At the end, component 4 decreased its criteria from 14 to 7 . This procedure guaranties that the comparison remains around 7 plus or minus 2 elements at a time. According to Saaty \& Ozdemir (2003), if the number of comparisons exceeds 9, the significance of the priorities' obteined is drastically reduced.

After grouping criteria in component 4, interdependences among criteria were determined by the Director of the Industrial Engineering Department and a Professor of the Department involved in the reaccreditation process. The resulting network of components is shown in Figure 5. We do not present the network with all the criteria because it is too big and the interdependences relations would turn impossible to recognize.

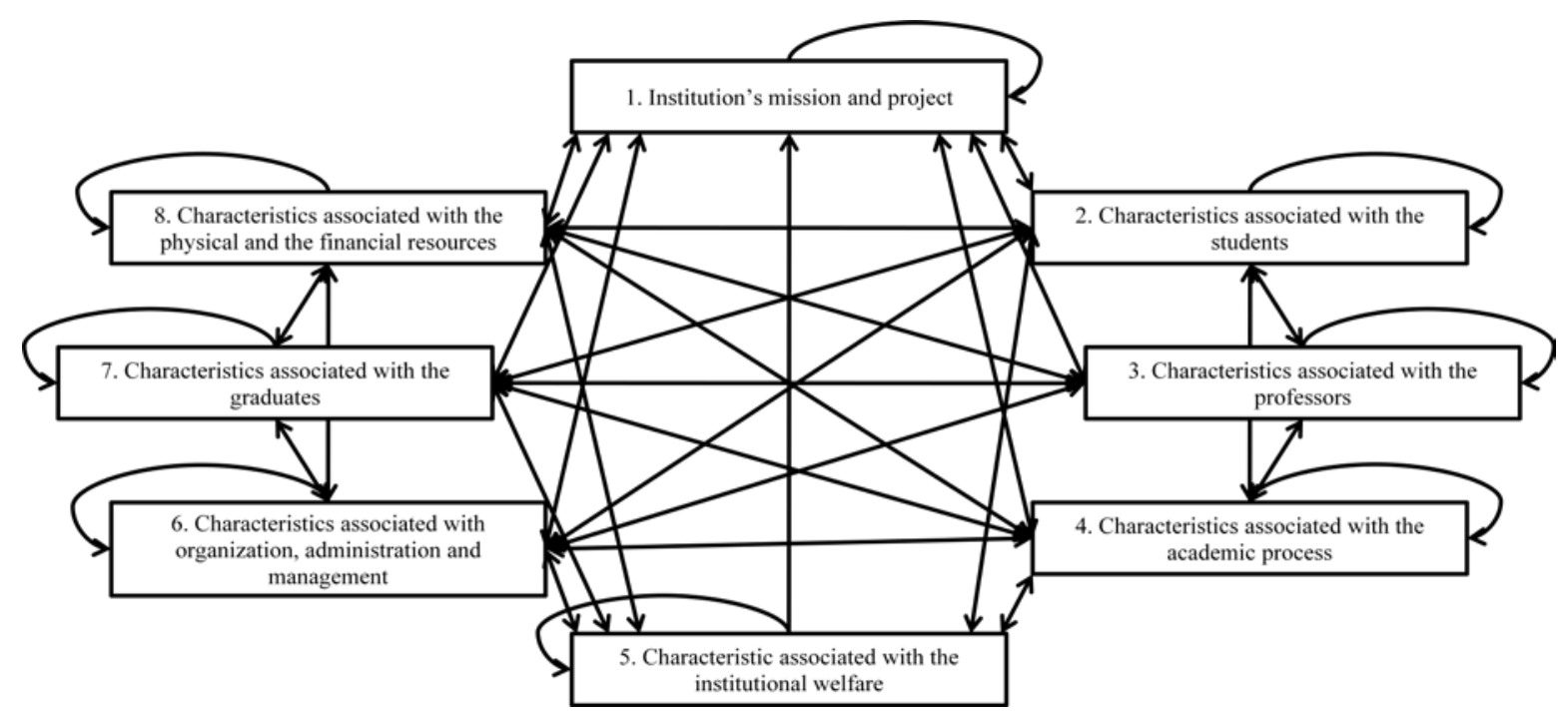

Figure 5. Components’ network

During the process of building the network, the Director of the Industrial Engineering Department and a Professor grouped the criterion 5 and 6, admission mechanisms and admitted students' number and quality. These criteria were associated because they generated the same relation of influence among the other elements of the model. After all, the criterions' grouping was done; the model ended up with 34 criteria. 


\subsection{Experts questionnaire}

In this step, a group of ten academic members who work at the Industrial Engineering Department at different divisions established the judgments of the pairwise comparisons matrices. In the meeting, they were asked to work in couples. Afterwards, they received the questionnaires and a sheet with the definition of the criteria and the components. The academics that filled the questionnaires were asked to respond the questions focusing in how the program's current performance is respect to the performance that the program should have. In total, we distributed in equal parts among the groups 104 pairwise comparison matrices of criteria and 8 pairwise comparison matrices of components. The questions had the format shown in Figure 6.

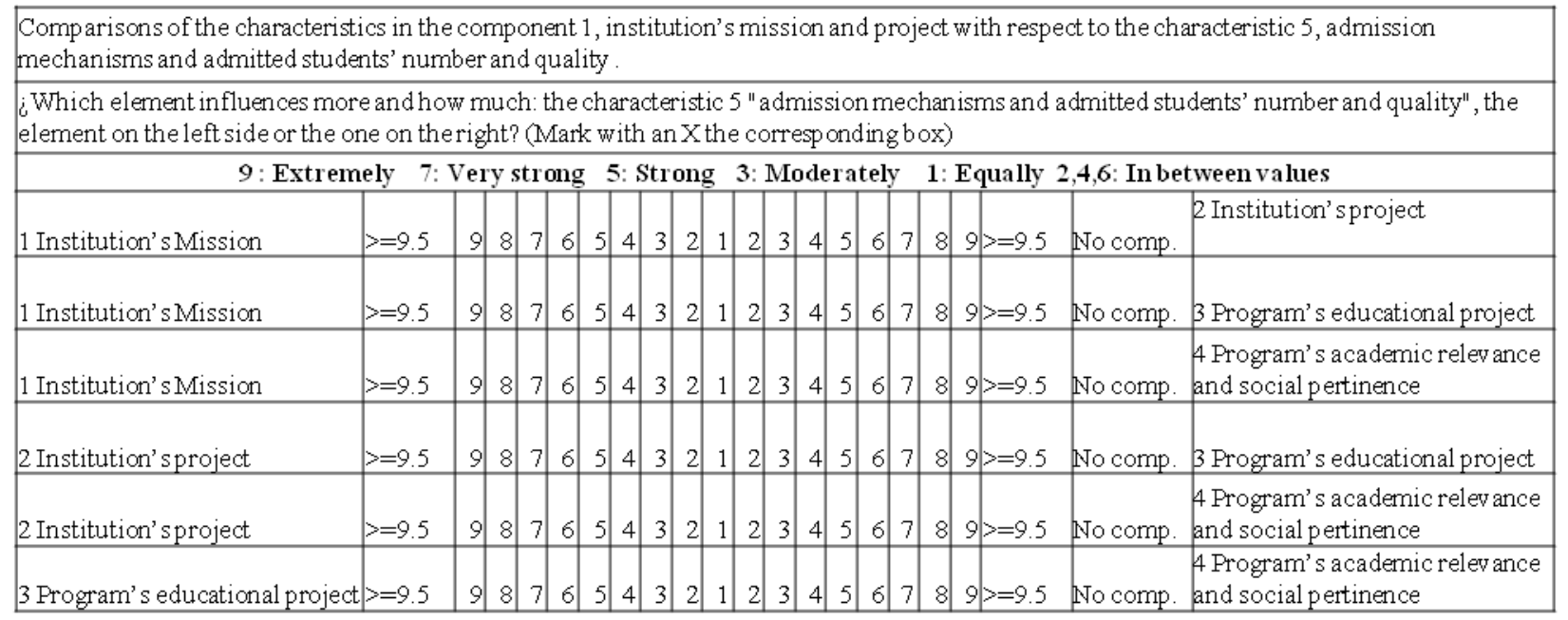

Figure 6. Questionnaire example

\subsection{Priorities' weights calculation}

We obtained the priorities derived from paired comparison matrices using the software Super Decisions. In order to obtain those weights first, we created the components and its criteria in the software. After, we marked the relations of influence among criteria. Finally, we introduced the information of the pairwise comparison matrices. Automatically, the software calculated the eigenvector of priorities and the C.R. In all the pairwise comparison matrices the consistency ratio was less than 0.2, which is a tolerable C.R. according to Saaty (2001, p. 57).

In the remaining of this section we show, following by an example, the procedure that Super Decision executes for obtaining the priorities' weights of the components and the criteria. Table 2 shows the C.R. and the priorities' weights or the eigenvector for the pairwise comparison matrix of Figure 6.

Table 2. Pairwise comparison among criteria within component 1 with respect to criterion 5

\begin{tabular}{|l|l|l|l|l|l|}
\hline & Criterion 1 & Criterion 2 & Criterion 3 & Criterion 4 & Eigenvector \\
\hline Criterion 1 & 1 & 2 & 2 & 3 & 0.4155 \\
\hline Criterion 2 & $1 / 2$ & 1 & 2 & 3 & 0.2926 \\
\hline Criterion 3 & $1 / 2$ & $1 / 2$ & 1 & 2 & 0.1849 \\
\hline Criterion 4 & $1 / 3$ & $1 / 3$ & $1 / 2$ & 1 & 0.1070 \\
\hline Note: C.R. $=0.0266$ &
\end{tabular}




\section{Lesmes, M. Castillo, R. Zarama/ Application of ANP to establish weights}

The C.R. in Table 2 indicates that the comparisons done are consistent. The eigenvector represents the priorities of each criterion in the component 1 , institution's mission and project with respect to the criteria 5 of component 2, admission mechanisms, and admitted students' number and quality, as vector D shows.

$$
D=\left[\begin{array}{l}
0.4155 \\
0.2926 \\
0.1849 \\
0.1070
\end{array}\right]
$$

We made the other comparisons of the criteria in the component 1 with respect to each criterion in the component 2 in order to calculate the 4 eigenvectors needed to form matrix $\mathrm{W}_{12}$. The first vector, moving from left to right, corresponds to vector D. The second vector corresponds to the elements' comparison of the component 1 with respect to criterion 7, students' retentions and dropout. The zeros of the vector imply that none of the elements of institution's mission and project influences criterion 7. The last vector implies that only institution's mission, criterion 1, influences students' regulations, criterion 9.

$$
W_{12}=\left[\begin{array}{llll}
0.4155 & 0.0000 & 0.6667 & 1.0000 \\
0.2926 & 0.0000 & 0.3333 & 0.0000 \\
0.1849 & 0.0000 & 0.0000 & 0.0000 \\
0.1070 & 0.0000 & 0.0000 & 0.0000
\end{array}\right]
$$

Following the same procedure for calculating all the eigenvectors, Super Decision linked them up to shape the unweigthed supermatrix, which has the structure shown in Figure 3. We do not show the supermatrix because its dimension is too big (34 columns, 34 rows).

The next step is to obtain the components matrix. The experts' questionaire provided us with all the jugdments that Super Decision needs for being able to calculate the components matrix shown in Table 3. In the matrix, the components on the left influence on each component on the top.

Table 3. Components matrix

\begin{tabular}{|c|c|c|c|c|c|c|r|r|}
\hline Component & 1 & 2 & 3 & 4 & 5 & 6 & 7 & 8 \\
\hline 1 & 0.44716 & 0.06574 & 0.10483 & 0.15763 & 0.32437 & 0.15201 & 0.20248 & 0.11948 \\
\hline 2 & 0.05591 & 0.00611 & 0.03392 & 0.05823 & 0.15261 & 0.04778 & 0.10149 & 0.04974 \\
\hline 3 & 0.09939 & 0.21620 & 0.39342 & 0.15895 & 0.00000 & 0.05407 & 0.08339 & 0.03684 \\
\hline 4 & 0.09939 & 0.23953 & 0.25681 & 0.44928 & 0.08311 & 0.06293 & 0.03722 & 0.03519 \\
\hline 5 & 0.00000 & 0.10843 & 0.00000 & 0.01936 & 0.00000 & 0.00000 & 0.02917 & 0.06850 \\
\hline 6 & 0.09939 & 0.19381 & 0.05217 & 0.06757 & 0.14168 & 0.51516 & 0.05022 & 0.17941 \\
\hline 7 & 0.09939 & 0.05393 & 0.02075 & 0.02650 & 0.14168 & 0.02920 & 0.46624 & 0.03966 \\
\hline 8 & 0.09939 & 0.11625 & 0.13811 & 0.06250 & 0.15655 & 0.13885 & 0.02979 & 0.47118 \\
\hline
\end{tabular}

Then, Super Decisions used the priorities from Table 3 to weight the corresponding blocks of the unweighted supermatix in order to make it stochastic. Afterwards, the software raised the weighted supermatrix into large powers until it stabilizes to four decimal places (Saaty T. L., 2004). The resultant priorities when the weighted supermatrix stabilizes are the weights that we propose to use in the reacreditation. 


\section{Comparison of the results obtained using ANP and direct weight assignation}

In Table 4 we show the relative importance of the components obtained by the direct weight assignation method and the ANP method. The weigths that the 4 groups assigned to each of the components, using the direct assignation method, were averaged to facilitate the comparison of the results.

We used Super Decisions to calculate the weights of the components. To compute their weights we added up the limit priorities of the criteria that belonged to each component. As shows Table 4, the results that we obtained were significantly different from those obtained with the direct assignation method. The ANP model results indicate that the source components of the network had the higher weights, whereas the sink components of the network had the lowest weights. Before continuing, we must clarify that the source components are called so because the proportion of criteria within the component that influences on other criteria is greater than the influences they receive; the same argument works for the sink components. For example, institution's mission and project, component 1 , has de highest priority because the elements within this component influence on most of the elements in the model. This is expected because the elements in component 1 define the institution's objetives and represent the academic and administrative general guidelines. The same happens with the component with the second highest priority, component 6, characteristics associated with the organization, administration and management. This component's high priority is product of its influence on most of the elements in the network, which happens as it defines the university's management processes and allows carrying out the mission within the organization. On the other hand, characteristics associated with the graduates, component 7 , has the second lowest weight because the elements within that component are considered as sink components, considering that the graduates of an undergraduate program are the output of the academic process. The component with the lowest weight is component 5 , characteristics associated with the institutional welfare. This low priority is expected because the component only has one criterion within. The other weights obtained are difficult to explain because the network is too dense and it is difficult to identify the relation of influence among criteria. However, we list the order in which they were classified according to the weight they obtained, from highest to lowest. Component 8, characteristics associated with the physical and the financial resources, is ranked $3^{\text {rd }}$. Component 4 , characteristics associated with the academic process, is ranked $4^{\text {th }}$. Component 3 , characteristics associated with the professors, is ranked $5^{\text {th }}$. And component 2, characeristics associated with the students, is ranked $6^{\text {th }}$.

Table 4. Components' weights

\begin{tabular}{|l|r|r|r|r|}
\hline & \multicolumn{2}{|l|}{$\begin{array}{l}\text { Direct weight } \\
\text { assignation method }\end{array}$} & \multicolumn{2}{l|}{ ANP method } \\
\hline Component & $\begin{array}{l}\text { Averaged } \\
\text { Weights }\end{array}$ & \multicolumn{1}{l|}{ Rank } & Weights & \multicolumn{2}{l|}{ Rank } \\
\hline 1 & 0.13 & 4 & 0.24 & 1 \\
\hline 2 & 0.16 & 3 & 0.04 & 6 \\
\hline 3 & 0.17 & 2 & 0.12 & 5 \\
\hline 4 & 0.19 & 1 & 0.14 & 4 \\
\hline 5 & 0.06 & 6 & 0.01 & 7 \\
\hline 6 & 0.07 & 5 & 0.23 & 2 \\
\hline 7 & 0.16 & 3 & 0.04 & 6 \\
\hline 8 & 0.06 & 6 & 0.18 & 3 \\
\hline
\end{tabular}


Table 5 shows the weights of the criteria components obtained by the direct weight assignation method and the ANP method. To compute the weights of the criterion using the ANP method we took from Super Decisions the limit priorities' weights normailized by the components.

Table 5. Weights of the criteria

\begin{tabular}{|c|c|c|c|c|c|}
\hline $\begin{array}{l}\text { Components } \\
\text { and Criteria }\end{array}$ & $\begin{array}{l}\text { ANP } \\
\text { Weights }\end{array}$ & $\begin{array}{l}\text { Directly } \\
\text { Assigned } \\
\text { weights }\end{array}$ & $\begin{array}{l}\text { Components } \\
\text { and Criteria }\end{array}$ & $\begin{array}{l}\text { ANP } \\
\text { Weights }\end{array}$ & $\begin{array}{l}\text { Directly } \\
\text { Assigned } \\
\text { weights }\end{array}$ \\
\hline \multicolumn{3}{|c|}{ Component 1. Institution's criteria } & Criterion 22 & \multirow[t]{3}{*}{0.14} & 0.09 \\
\hline Criterion 1 & 0.30 & 0.15 & Criterion 23 & & 0.06 \\
\hline Criterion 2 & 0.36 & 0.20 & Criterion 24 & & 0.07 \\
\hline Criterion 3 & 0.28 & 0.40 & Criterion 25 & 0.22 & 0.08 \\
\hline Criterion 4 & 0.06 & 0.25 & Criterion 26 & \multirow[t]{2}{*}{0.25} & 0.05 \\
\hline \multicolumn{3}{|c|}{ Component 2. Students' criteria } & Criterion 27 & & 0.05 \\
\hline Criterion 5 & \multirow[t]{2}{*}{0.21} & 0.15 & Criterion 28 & 0.08 & 0.08 \\
\hline Criterion 6 & & 0.30 & Criterion 29 & \multirow[t]{3}{*}{0.08} & 0.06 \\
\hline Criterion 7 & 0.16 & 0.20 & Criterion 30 & & 0.07 \\
\hline Criterion 8 & 0.49 & 0.20 & Criterion 31 & & 0.07 \\
\hline Criterion 9 & 0.14 & 0.15 & \multicolumn{3}{|c|}{ Component 5. Institutional welfare crt. } \\
\hline \multicolumn{3}{|c|}{ Component 3. Professors' criteria } & Criterion 32 & 1.00 & 1.00 \\
\hline Criterion 10 & 0.08 & 0.16 & \multicolumn{3}{|c|}{ Component 6. Management criteria } \\
\hline Criterion 11 & 0.10 & 0.14 & Criterion 33 & 0.45 & 0.27 \\
\hline Criterion 12 & 0.10 & 0.15 & Criterion 34 & 0.10 & 0.21 \\
\hline Criterion 13 & 0.32 & 0.13 & Criterion 35 & 0.42 & 0.25 \\
\hline Criterion 14 & 0.16 & 0.12 & Criterion 36 & 0.03 & 0.27 \\
\hline Criterion 15 & 0.16 & 0.10 & \multicolumn{3}{|c|}{ Component 7. Graduates criteria } \\
\hline Criterion 16 & 0.05 & 0.10 & Criterion 37 & 0.34 & 0.40 \\
\hline Criterion 17 & 0.03 & 0.10 & Criterion 38 & 0.27 & 0.30 \\
\hline \multicolumn{3}{|c|}{ Component 4 . Academic process crt. } & Criterion 39 & 0.39 & 0.30 \\
\hline Criterion 18 & 0.11 & 0.09 & \multicolumn{3}{|c|}{ Component 8. Resources criteria } \\
\hline Criterion 19 & & 0.09 & Criterion 40 & 0.26 & 0.35 \\
\hline Criterion 20 & & 0.08 & Criterion 41 & 0.44 & 0.35 \\
\hline Criterion 21 & 0.12 & 0.06 & Criterion 42 & 0.30 & 0.30 \\
\hline
\end{tabular}

At the end, the priorities' weights obtained with the ANP model were combined with the weights directly assigned due to the need of join two effects. One is the effect of the direct assignation method that considers the improvements of the university and the department with respect to the past performance on each of the criteria. The second is the effect of the ANP method that reflects the relative priorities of the criteria while having under consideration their relations of influence. 


\section{Conclusions}

It is important to remark that the ANP model's development was essential. This is so because the weights that we obtained were taken into account to evaluate the program and, consequently, to recognize its offered quality. The ANP model performing gave full understanding of the level of importance that a criterion can take according to its interrelationship with other elements of the model. A benefit of the ANP model is that allows assessing the consistency of the judgments, which is not possible to evaluate with the method of assigning weights by consensus. Another positive aspect of the ANP model is that facilitates the process of assigning weights because splits up the problem into smaller parts where the group of academics can have a manageable discussion, and where only two criteria can be compared in order to assign the judgments. On the other hand, the disadvantage of the ANP model is that it requires filling in a lot of questionnaires; to be exact, 112 pairwise comparison matrices for this accreditation model. We recommend the CNA to reduce the number of criteria because we saw that some of them can join other criteria to which they are related. This grouping process would improve the self-evaluation stage of the re-accreditation process by reducing the number of redundant comparison.

\section{REFERENCES}

Consejo Nacional de Acreditación. (2006, November). Publicaciones: Lineamientos Para la Acreditación de Programas. Retrieved March 7, 2009, from www.cna.gov.co

Consejo Nacional de Acreditación. (2006, November). Publicaciones: Orientación para la Evaluación Externa con Fines de Acreditación Institucional. Retrieved March 7, 2009, from www.cna.gov.co

Lin, Y.-H., et al. (2008). Research on Using ANP to Establish a Performance Assessment Model for Business Intelligence Systems. Experts Systems with Applictations , doi:10.1016/j.eswa.2008.03.004.

Saaty, T. L. (2001). Decision Making with Dependence and Feedback: The Analytic Network Process (Second ed.). Pittsburgh, USA: RWS Publications, 4922 Ellsworth Avenue,Pittsburgh, PA 15213 USA.

Saaty, T. L. (2004, Jenuary 13). Lect9-ANP.ppt The Essentials of the Analytic Network Process with Seven Examples. . Retrieved February 10, 2008, from sitio Web Super Decisions Software: http://www.superdecisions.com/ saaty/Powerpoint\%20Lecture\%20Slides/

Saaty, T. L. (2008). Relative Mesuarement and Its Generalization in Decision Making Why Pairwise Comparisons are Central in Mathematics for the Measurement of Intangible Factors The Analytic Hierarchy/Network Process. RACSAM , 102 (2), 251-318.

Saaty, T. L. (2005). Theory and Applications of the Analytic Network Process. Pittsburgh, USA: RWS Publications.

Saaty, T. L., \& Ozdemir, M. S. (2003). Why the magic number seven plus or minus two. Mathematical and Computer Modelling , 383, 233-244.

Saaty, T. L., \& Vargas, L. G. (2006). Decision Making with the Analytic Network Process Economic, Political, Social and Technological Applications with Benefits, Opportunities, Cost and Risk. United States of America: Springer. 